\begin{tabular}{l|c|c}
\hline $\begin{array}{c}\text { ISSN 2525-4812 (versão online) } \\
\text { ISSN 2238-7641 (versão impressa) } \\
\text { http://www.revistaterceiramargem.com/ } \\
\text { index.php/terceiramargem/index }\end{array}$ & $\begin{array}{c}\text { Recebido em: 3/5/2019 } \\
\text { Aprovado em: 6/1/2020 } \\
\text { Período de publicação: jan., 2021 }\end{array}$ & $\begin{array}{c}\text { Revista Terceira } \\
\text { Margem Amazônia } \\
\text { (v. 6 • n. especial 16 • Jan. 2021) }\end{array}$ \\
\hline Como citar o artigo: \\
$\begin{array}{l}\text { SILVA, B. M.; SILVA, D. F.; SILVA, L. G. F.; SILVA, D. C .C. Agricultura Familiar e produção orgânica : estudo de caso da asso- } \\
\text { ciação de orgânicos do Tapajós. Revista Terceira Margem Amazônia. v. 6, n. especial 16, p. 155-161, 2021. DOI: http://dx.doi. } \\
\text { org/10.36882/2525-4812.2021v6i16.ed.esp.p155-161 }\end{array}$ \\
\hline
\end{tabular}

\title{
AGRICULTURA FAMILIAR E PRODUÇÃO ORGÂNICA: ESTUDO DE CASO DA ASSOCIAÇÃO DE ORGÂNICOS DO TAPAJÓS
}

\author{
Bruna Martins da Silva \\ Débora Freitas da Silva \\ Luiz Gonzaga Feijão da Silva ${ }^{3}$ \\ Deyse Cristina Coelho da Silva ${ }^{4}$
}

Resumo: Este artigo tem como objetivo demonstrar a evolução da renda da Associação de Produtores Orgânicos dos municípios Santarém e Mojui dos Campos, no estado do Pará, no contexto da agricultura familiar, por meio de estudo da comercialização dos produtos na Feira da Agricultura Familiar, da Universidade Federal do Oeste do Pará. A pesquisa foi realizada no município de Santarém, no estado do Pará, com os produtores da Associação de Orgânicos do Tapajós, no ambiente da universidade. Os materiais utilizados para obter os resultados foram: aplicação de questionários aos produtores em todas as edições da feira e pesquisa bibliográfica para aprofundamento do conhecimento teórico. A partir dos dados coletados na pesquisa foi possível concluir que há potencial de crescimento na venda dos produtos, resultado esse positivo para os produtores, haja vista que o percentual de venda esteve acima de $50 \%$, significa que não há prejuízos.

Palavras-chave: agricultura familiar, produção orgânica, ações extensionistas.

\footnotetext{
Graduanda de Administração na Universidade Federal do Oeste do Pará (Ufopa), Belém, PA.

E-mail: brunabb21@hotmail.com

(D) https://orcid.org/0000-0003-2713-5637

2 Engenheira química, assistente administrativa das Centrais Elétricas do Pará (Celpa), Belém, PA. E-mail: débora_silva80@hotmail.com

(D) https://orcid.org/0000-0003-4959-1713

3 Economista, M. Sc. em Planejamento do Desenvolvimento, professor efetivo na Universidade Federal do Oeste do Pará, Belém, PA. E-mail: luizgonzagafs@yahoo.com.br

(D) https://orcid.org/0000-0002-9035-0084

${ }^{4}$ Graduanda em Ciências Econômicas, Universidade Federal do Oeste do Pará, Belém, PA.

E-mail: deysecristinacs@gmail.com

(D) https://orcid.org/0000-0001-5934-3241
} 


\title{
FAMILY FARMING AND ORGANIC PRODUCTION: A CASE STUDY OF THE TAPAJÓS ORGANIC ASSOCIATION
}

\begin{abstract}
This article aims to demonstrate the evolution of the income of the Association of Organic Producers of the municipalities Santarém and Mojui dos Campos in the state of Pará in the context of family farming, through a study of the marketing of products at the Fair of Family Farming, at the Federal University of the West do Pará. The research was carried out in the municipality of Santarém in the State of Pará, with producers from the Tapajós Organic Association, in the University environment. The materials used to obtain the results were: application of questionnaires to producers in all editions of the fair, and bibliographic research to deepen theoretical knowledge. From the data collected in the survey it was possible to conclude that there is potential for growth in the sale of products, a positive result for producers, given that the percentage of sales was above $50 \%$, it means that there are no losses.
\end{abstract}

Keywords: family farming, organic production, extensionist actions.

\section{Introdução}

A partir de 1990 houve um crescimento nos estudos sobre desenvolvimento rural no Brasil. Abordagens econômicas, políticas e sociais trouxeram novas perspectivas para o meio rural, como conceitos de economia verde e desenvolvimento sustentável (SCHINEIDER, 2010).

Tais conceitos estão atrelados em decorrência do crescimento e desenvolvimento de localidades, que logo se transformam e refletem no âmbito regional. Essa trajetória de desenvolvimento só é possível se os agentes locais tiverem iniciativas inovadoras em relação ao que produzem, assim como no modo como conduzem suas vidas na sociedade, principalmente no que tange ao conceito de coletividade, em que se produz de forma a alcançar objetivos comuns em prol de um todo, ou seja, quando os atores dessa localidade passam a compreender a realidade e as mudanças ao seu redor e a construir estratégias que possam os colocar dentro do novo ambiente social e econômico.

\footnotetext{
O primeiro, e talvez o mais importante, fator a ser destacado está relacionado com a trajetória das discussões em torno da agricultura familiar e de seu potencial como modelo social, econômico e produtivo para a sociedade brasileira. Por certo, tanto a agricultura familiar como os agricultores, que hoje são assim denominados, sempre existiram, e não se trata de uma novidade. Mas é mister reconhecer que foi na primeira metade da década de 1990 que esta noção se firmou como uma categoria política, sendo em seguida assimilada por estudiosos e por formuladores de políticas, o que lhe confere atualmente uma extraordinária legitimidade a tal ponto de se constituir como referência em oposição a outras noções igualmente poderosas, como a de agronegócio, por exemplo (SCHNEIDER, 2010, p. 514).
}

Segundo Abramovay (1992), a agricultura familiar tem papel fundamental por sua capacidade de inovação, dinamização e seu caráter social, que foi reflexo de desenvolvimento em grandes nações desenvolvidas. Mesmo em cenários de concorrência, em que os produtores precisem inovar constantemente, é perceptível o destaque da produção familiar. 
Nesse contexto é importante reconhecer que os pequenos empreendimentos familiares estão sobrevivendo e superando os desafios de se manter em um ambiente econômico concorrido por consequência do auxílio de tecnologias, que cada vez mais tomam espaço no meio rural. No Brasil, a evolução de trabalhos que discutem a temática se intensifica a cada dia (SILVA, 2007).

Nesse sentido vale ressaltar as diferentes formas de organização nos ambientes rurais familiares, em sua maioria o mundo rural tem suas peculiaridades, os empreendimentos organizam suas atividades da melhor forma possível para obter não somente a subsistência, mas sim com intuito de comercializar o excedente. A grande característica desses pequenos empreendimentos é a inclusão de renda no ambiente familiar (COSTA, 2016).

A agricultura familiar se destaca por sua forma de produzir, organizada basicamente pelos membros da família. Esse modo de produção valoriza a mão de obra dos componentes da família, cada com sua função na unidade familiar, e todos trabalham para o bem-estar da família.

Ela traz os conceitos de cultura, tradição e identidade, há um resgate de um bem-estar que acaba levando populações das grandes cidades a buscar uma vida mais saudável, valorizando os alimentos sem agrotóxicos, com matéria-prima com menor processamento industrial. Também é parte desse processo o desenvolvimento local, a agricultura como um importante ator social, mantendo as dinâmicas do meio rural-urbano (ALTAFIN, 2007).

A agricultura familiar é conhecida como alternativa para o desenvolvimento de uma localidade ou região, com taxas de redução de problemas como a pobreza, buscando-se inserir tal modo de produção num modelo que diminua os danos ao meio ambiente e que esse método traga benefícios para os produtores que têm como desafio o mercado competitivo (SILVA, 2007).

Entre as diferentes correntes de agricultura alternativa ao padrão convencional, a da agricultura orgânica é atualmente a mais difundida, sendo inclusive reconhecida junto aos consumidores como sinônimo de todas as outras. Essas correntes representam a busca de uma nova prática agrícola, que, no entanto, é moldada em função do processo social em que está inserida, determinando diferentes modos de encaminhamento tecnológico e de inserção no mercado, que influenciam diretamente sobre o grau em que os limites teóricos da agroecologia são respeitados (ASSIS, 2002).

Uma das características da agricultura familiar é a diversificação em relação aos produtos convencionais e orgânicos, a produção orgânica cresce a cada dia, isso porque a ideia de se produzir pensando na preservação do meio ambiente é fundamental para as economias. A produção orgânica exige mais atenção e cuidados, já que é um desafio não utilizar fertilizantes e agrotóxicos. Os alimentos orgânicos são produzidos usando recursos da natureza, como adubos naturais e técnicas de sistemas agroflorestais (ALVES, 2012).

Esse sistema procura estar o mais próximo possível do natural, que é o contrário do que acontece com a produção convencional, em que o processo como um todo compromete o solo, e isso leva à dependência do uso de fertilizantes para que haja alta produção e controle de pragas usando produtos de alto risco para a saúde humana. 
O processo cuidadoso de produzir de forma ecológica permite classificar os produtos orgânicos como muito importantes, permite maior agregação de valor ao produto, pois contribui em seu processo para o desenvolvimento sustentável.

Nesse sentido tem-se como objetivo geral do trabalho demonstrar a evolução da renda da Associação de Produtores Orgânicos dos municípios Santarém e Mojui dos Campos, no estado do Pará, no contexto da agricultura familiar, por meio de estudo da comercialização dos produtos na Feira da Agricultura Familiar da Universidade Federal do Oeste do Pará. A pesquisa foi realizada no município de Santarém, no estado do Pará, com os produtores da Associação de Orgânicos do Tapajós no ambiente da universidade. Os materiais utilizados para obter os resultados foram: aplicação de questionários aos produtores em todas as edições da feira e pesquisa bibliográfica para aprofundamento do conhecimento teórico.

\section{Material e Métodos}

A feira é uma ação do Projeto de Extensão Incubadora de Empreendimentos Solidários, em parceria com a Pró-Reitoria de Cultura, Comunidade e Extensão (PROCCE). Tem como objetivo proporcionar um ambiente de integração entre a comunidade acadêmica e os agricultores familiares, constituindo-se em um canal de comercialização dos produtos dos agricultores, além de ser um espaço para alunos e servidores adquirirem produtos a preço acessível e com qualidade, garantindo maior segurança alimentar.

O trabalho contou com pesquisa de campo e bibliográfica. A coleta de dados foi feita por meio da aplicação de questionários aos produtores da Associação de Produtores Orgânicos do Tapajós no Ambiente da Universidade (Figura 1), local onde acontece a feira nos meses de julho, agosto, setembro e outubro de 2016, e fevereiro, março, abril, maio, junho, julho, agosto, setembro e novembro de 2017. Os dados foram coletados e organizados mensalmente por meio da aplicação de questionários com informações de produtos, quantidade ofertada, quantidade vendida e o preço por quilograma de cada produto, assim foi possível chegar às receitas da associação.

As tabulações dos dados foram feitas com auxílio do programa Excel, criando-se tabelas e gráficos para melhor compreensão dos dados.

Figura 1. Feira da agricultura familiar e produtos orgânicos.
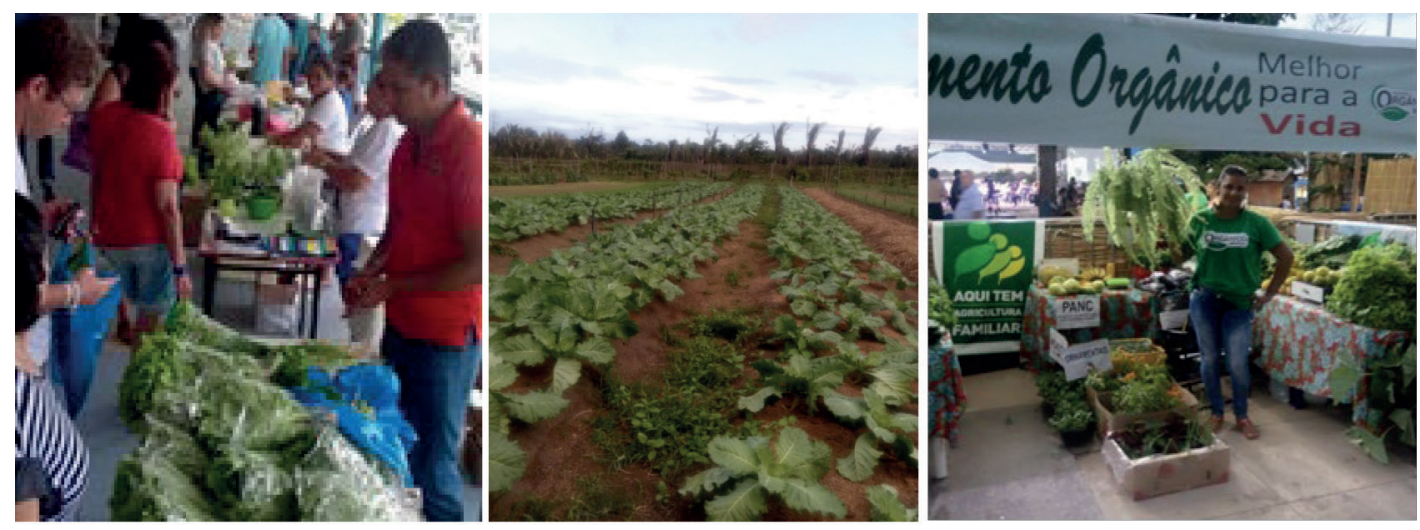

Fonte: Incubadora de Empreendimentos Solidários (2017). 


\section{Resultados e Discussão}

Durante toda a pesquisa observou-se que a junção de boas práticas de produção e estratégias de oferta do produto em parceria com a universidade trouxe resultados positivos. Além de ser mais um mercado conquistado pelos produtores, houve maior benefício aos consumidores docentes, discentes e à sociedade em geral.

A feira possibilita aos produtores a comercialização do excedente da sua produção diretamente para os consumidores, que passam a ter acesso a alimentos saudáveis a preço justo, sem sobressaltos nos contratos informais já estabelecidos na feira. Esse processo traz para si a importância do ambiente institucional e os custos de transação, visto que a feira é uma ação de extensão com objetivo de maior coordenação e governança nas transações inerentes a esse canal de comercialização, contribuindo para o desenvolvimento local.

A feira conta com a participação de cinco associações e quatro cooperativas e funciona das $8 \mathrm{~h}$ às $12 \mathrm{~h}$ às quintas-feiras. A Associação de Orgânicos do Tapajós conta com a participação de seis produtores. A feira é avaliada, em cada edição, pelos frequentadores e tem público de aproximadamente 150 pessoas que a frequentam em cada edição (pessoas que assinaram a lista de frequência). Desse total de pessoas, $96 \%$ avaliam a feira como boa ou excelente.

A Tabela 1 faz um resumo da receita e da receita potencial da venda de cada mês em que houve feira na universidade no período analisado. Os principais produtos comercializados foram: alface, couve, polpas, castanha-do-pará, rúcula, pimentinha, banana, acerola, maracujá, limão e macaxeira.

Tabela 1. Receitas e percentuais de venda da associação.

\begin{tabular}{|ccccc|}
\hline Meses & Ano & Receita $(\mathrm{R} \$)$ & Receita potencial $(\mathrm{R} \$)$ & \% de venda \\
\hline Julho & 2016 & $1.023,00$ & $1.847,90$ & 55 \\
\hline Agosto & 2016 & $1.009,75$ & $1.121,75$ & 90 \\
\hline Setembro & 2016 & $1.011,80$ & $1.457,10$ & 69 \\
\hline Outubro & 2016 & 989,45 & $1.616,80$ & 61 \\
\hline Fevereiro & 2017 & $1.702,60$ & $2.391,00$ & 71 \\
\hline Março & 2017 & $4.038,80$ & $5.150,50$ & 71 \\
Abril & 2017 & 501,00 & 703,00 & 87 \\
Maio & 2017 & $1.016,00$ & $1.169,25$ & 66 \\
\hline Junho & 2017 & 883,00 & $1.328,00$ & 76 \\
Julho & 2017 & $1.191,00$ & $1.564,05$ & 72 \\
Agosto & 2017 & $3.202,50$ & $4.432,00$ & 73 \\
\hline Setembro & 2017 & $1.204,00$ & $1.643,00$ & 61 \\
\hline
\end{tabular}

Fonte: Incubadora de Empreendimentos Solidários (2017). 
Com esses dados é possível perceber que os produtores não estão tendo prejuízos ao comercializarem na feira, pois estão conseguindo vender mais de $50 \%$ da sua produção. Isso reforça a importância da produção orgânica e do papel das instituições como incentivadoras e parceiras dos empreendimentos.

\section{Considerações Finais}

O estudo mostrou breve apresentação sobre agricultura familiar e produção orgânica, bem como o desempenho na comercialização da produção da Associação de Produtores Orgânicos do Tapajós, por meio do Projeto de Extensão Incubadora de Empreendimentos Solidários da Universidade Federal do Oeste do Pará (Ufopa), trazendo a importância das ações extensionistas e mostrando resultados positivos para aumento da renda dos produtores e demonstrando que a universidade está cumprindo o seu papel na contribuição do desenvolvimento local.

A universidade, como organização que promove ações por meio dos projetos de extensão, tem papel preponderante no incentivo aos empreendimentos como associações e cooperativas a trabalharem de forma que os objetivos econômicos sejam alcançados, a relação produtores e consumidores seja fortalecida, o ambiente institucional seja propenso à ampliação de novos acordos tanto formais como informais e que a confiança nos produtos seja elevada a partir da diminuição da incerteza.

As ações do projeto Incubadoras de Empreendimentos Solidários, desde 2013, trouxeram resultados positivos aos empreendimentos que são assistidos pelo projeto, a feira organizada na Ufopa é resultado de esforços na construção de um ambiente de comercialização que possa ser ampliado e que sirva de oportunidade para produtores e comunidade acadêmica, tanto para consumir os produtos como para fornecer informações para as diversas áreas de conhecimentos, como objeto de estudo.

Todo esse arcabouço teórico e prático de acompanhamento da produção orgânica na associação tem grande importância para os estudos de desenvolvimento na região, bem como para que exemplos como esse sejam disseminados, contribuindo para o fortalecimento da agricultura familiar e da produção sustentável na região oeste do Pará.

\section{Agradecimentos}

À Universidade Federal do Oeste do Pará (Ufopa), por meio do Projeto de Extensão Incubadora de Empreendimentos Solidários, em nome do meu orientador, prof. M.Sc. Luiz Gonzaga Feijão da Silva, e aos demais colaboradores do projeto, acadêmicos que transformam objetivos em realidade. 


\section{Referências}

ABRAMOVAY, R. Paradigmas do capitalismo agrário em questão. São Paulo: Hucitec, 1992.

ALTAFIN, I. Reflexões sobre o conceito de agricultura familiar. 2007. (Biblioteca Digital da Questão Agrária Brasileira). Acesso em: 10 maio 2016. Disponível em: http://www.reformaagrariaemdados.org. br/biblioteca/artigo-e-ensaio/reflex\%C3\%B5es-sobre-o-conceito-de-agricultura-familiar. Acesso em: 20 maio 2018 .

ALVES, E. M. A importância da agricultura orgânica na visão social e ecológica. Revista F@pciência, v. 9, n. 1, 2012. Disponível em: http://www.cesuap.edu.br/fap-ciencia/edicao_2012/001.pdf. Acesso em: 19 maio 2018.

ASSIS, L. R. Agroecologia e agricultura orgânica: controvérsias e tendências. Revista Desenvolvimento e Meio Ambiente, n. 6, p. 67-80, jul./dez. 2002. Acesso em: 16 maio 2018.

COSTA, F. P. da. Agricultura familiar e sustentabilidade. 2016. Disponível em: http://www.infocos. org.br/publicacresol/upload/trabalhosfinal/251.pdf. Acesso em: 13 maio 2018.

SCHNEIDER, S. Situando o desenvolvimento rural no Brasil: o contexto e as questões em debate. Revista de Economia Política, v. 30, n. 3, p. 119, jul.-set. 2010.

SILVA, T. G. L. Sustentabilidade da agricultura familiar em assentamentos rurais no sudeste paraense. 2007. 295 f. Tese (Doutorado em Ciências) - Universidade Federal do Pará, Belém, PA. Disponível em: https://ainfo.cnptia.embrapa.br/digital/bitstream/item/104360/1/LuizGuilhermeTSilva.pdf. Acesso em: 21 maio 2018. 
